\title{
La función ejecutiva y su necesaria intervención en la materialización de los derechos constitucionales
}

\author{
The Intervention of the Executive Power in the Materialization of Constitutional Rights
}

Recibido: 28 de julio de 2017 - Revisado: 2 de noviembre de 2017 - Aceptado: 19 de febrero de 2018

\section{Juan Felipe Solórzano Quintero ${ }^{1}$}

\section{Resumen}

El escrito evidencia cómo el poder Ejecutivo adquiere un papel especial en la garantía de los derechos de la persona a partir de las transformaciones del modelo de Estado. Teniendo en cuenta lo anterior, se hace una serie de exigencias que permiten que, tanto la Administración como el Gobierno, se sometan a los postulados constitucionales. Sin embargo, en la actualidad el Ejecutivo no se ciñe del todo a la Norma Superior. Así, el presente artículo pretende tomar conceptos del derecho constitucional que permitirán dar génesis a los conceptos de buen gobierno y buena administración como principios que vienen a hacerle frente al quehacer errado de la Administración y el Gobierno. También permiten que su actuar se encamine a la protección de la persona, que debe ser el fin principal de la organización administrativa.

\section{Palabras clave}

Administración, Gobierno, buen gobierno, buena administración, prevención, principios administrativos, principios constitucionales.

\begin{abstract}
The article exposed how the Executive power acquires a special role in guaranteeing constitutional rights of the person from the transformations of the state model. On this basis, the constitution demands that the Administration and the Government comply the constitutional postulates fully. Nevertheless, in reality, the Executive does not wholly adheres to the constitutional norm. Consequently, this article aimed, through legal analysis, to take concepts from the constitutional law to create the basis for good government and good governance. Those principles come to confront the erroneous tasks of the governance and the government. They also allow the actions of both the administration and the government to be directed towards the protection of the person, which is their primary purpose.
\end{abstract}

\section{Keywords}

Administration, Government, Good Administration, Good Government, prevention, administrative principles, constitutional principles.

\footnotetext{
${ }^{1}$ Abogado con máster en Derecho Administrativo de la Universidad Colegio Mayor de Nuestra Señora del Rosario. Doctor de la Universidad de Salamanca y miembro de la red Alumni del Max-Planck-Institut für ausländisches öffentliches Recht und Völkerrecht.

Correo electrónico:

juansolorzano@usal.es

0000-0002-5260-6464

Citación:

Solórzano-Quintero, J. (2019). La Función ejecutiva y su necesaria intervención en la materialización de los derechos constitucionales. Civilizar: Ciencias Sociales y $\mathrm{Hu}$ manas, 19(36), 41-58. doi: 10.22518/ usergioa/jour/ccsh/2019.1/a03
} 


\section{Introducción}

El objeto del presente artículo es evidenciar la importancia que tienen el Gobierno y la Administración en la consecución de los derechos constitucionales, los que se refieren al postulado social en particular. Para sustentar la anterior afirmación nos basamos en tres premisas:

Primera, en el artículo 1, la Constitución política de 1991 preceptúa que Colombia es un Estado social y democrático de derecho, garante de los principios democráticos, de la dignidad humana y del interés general. De aquí se desprende el carácter social e interventor del Estado, el cual no solo pretende garantizar el aspecto formal de las normas, principalmente de los derechos, sino que debe incluir el aspecto material; mandato establecido en los artículos 2 y 5 de la Norma Superior.

La segunda se relaciona con la primera, ya que parte de la obligación del Estado de remover todas las rémoras que obstaculizan la garantía de los derechos de las personas. Esto implica una visión en que el principal objeto del Estado es promover cambios en busca de mejorar las condiciones de vida de sus habitantes. Por lo tanto, la satisfacción de las necesidades se dará al tener en cuenta la dignidad de la persona (Gómez Puente, 2002). Lo anterior implica que el individuo adquiere una primacía en torno al quehacer público, lo cual genera que el Estado promueva la participación en aspectos políticos, económicos y sociales. Todo esto debe darse conforme a los principios democráticos y al derecho.

Tercera, estas necesidades deben ser materializadas de alguna forma. Sin duda alguna el Gobierno y su brazo ejecutor (la Administración) permiten realizar y satisfacer las pretensiones sociales y la garantía de los derechos. Así, se espera que el poder Ejecutivo lleva a cabo todas las actividades tendientes a resguardar la dignidad de la persona, pero estas acciones no deben darse de forma desordenada, siempre deben ceñirse al postulado democráti- co, al social y al de derecho. Para ello, la Constitución ha establecido que la Administración debe seguir el interés general en todo momento, y por ello existe una serie de mandatos, principios y valores que obliga a que el ejecutivo actúe de manera adecuada; todos aquellos recogidos en los conceptos de buen gobierno y buena administración que, junto con el interés general, garantizarán la legalidad y la protección de los derechos del individuo.

La situación descrita pone de presente que la Administración y el Gobierno permiten que el Estado esté en sintonía con el dinamismo social. Esto implica una gran responsabilidad que redundará en su correcto funcionamiento, que no debe ser de abstención, propio del modelo liberal, sino que deberá ser partícipe e interventor en la consecución de los derechos, en particular los de carácter social que requieren de una intervención asidua.

Este trabajo se ciñe al análisis de la ciencia jurídica pública al tener como sustento el estudio de conceptos constitucionales que nos permitirán llegar a la formación de los principios de buen gobierno y buena administración. El trabajo se enmarca dentro de la metodología deductiva, ya que parte de elementos generales que permiten llegar al estudio de un aspecto particular que es el comportamiento del poder ejecutivo. También se sigue un método de investigación documental (Solano y Sepúlveda, 2008), lo cual lleva a concluir que este documento es de revisión bibliográfica y conceptual.

Para desarrollar este trabajo analizaremos la evolución del Estado, particularmente desde finales del siglo XVII, a fin de evidenciar cómo, paso a paso, la función ejecutiva adquirió un carácter relevante en la garantía de los derechos sociales. Es por ello que, para el correcto ejercicio de la organización administrativa, se impone constitucionalmente la observancia al interés general como derrotero del ejercicio de la actividad pública. No obstante, existen otros principios valores y mandatos constitucionales que 
vendrán a fortificar el interés general y reposan en el buen gobierno y la buena administración. Estos dos conceptos devendrán en principios, para ello nos sustentaremos en la teoría de los derechos fundamentales de Alexy, que harán frente a los constantes hechos de corrupción y mala actuación por parte del Ejecutivo. Así, se le recordará permanentemente al Gobierno y a la Administración su sometimiento total a la Constitución.

No resulta ilógico hablar de buena administración y buen gobierno, si bien en ellos subyacen normas constitucionales de antaño. En la actualidad, existen actos de mal ejercicio de la función ejecutiva que hacen necesario recordar que su razón de ser no es otra que la garantía y protección de la persona, que da génesis a todo el ordenamiento jurídico, en consecuencia, a todas las instituciones públicas.

\section{La evolución del Estado y la progresiva importancia de la función ejecutiva en la consecución del postulado social}

Hablar de los asuntos públicos nos remite a Grecia, podemos ver como desde la época de la oración fúnebre de Pericles, pasando por Platón y llegando a Aristóteles, lo público era de máxima interés y la pregunta de quién debía dirigir estos asuntos era fundamental. Fue en ese entonces cuando Platón mencionó en La República la necesidad de designar personas capaces para estos objetivos (Sabine, 2000). Esto es una muestra de que el estudio de la organización pública y las relaciones de poder siempre han estado implícitas a las cuestiones que conciernen a los ciudadanos, a lo largo de la historia.

Fue ya en la época moderna, producto de los movimientos ilustrados del siglo XVII, en que el derecho administrativo adquirió gran importancia (García de Enterria y Fernández Rodríguez, 2006; Rivero Ortega, 2016). Esto supuso una nueva forma de pensar el Estado. El objetivo que se trazó fue la imposición de límites al ejercicio del poder por parte del monarca, principalmente a través de sometimiento a la ley, la división de los poderes y la consagración de un catálogo de derechos. Fue en el siglo XVIII ${ }^{1}$, cuando se empezó a discutir abiertamente el tema de los derechos que gozaba el hombre.

La libertad fue el principio que se caracterizó por fundamentar el ordenamiento jurídico (Peces-Barba Martínez y Dorado Porras, 2003). Según Rousseau (2013) se puede hablar de tres estadios de libertad, que permiten el bienestar del individuo.

Encontramos así la libertad de elección, que le permite a la persona decidir a voluntad, por eso también se la denomina libertad de arbitrio, o natural. Rousseau (2013) la define como aquella que es primigenia, o previa al contrato social y es la que hace que se alcance la libertad moral, que es la materialización del hombre libre. Pero para llegar a la libertad moral no podemos basarnos solo en la libertad inicial o de elección, por el contrario, debe participar la libertad medial (social, política y jurídica) la cual a través de los derechos establece una organización en la vida social en función de la libertad de elección. En otras palabras, la libertad medial permite el mantenimiento del bien público y tiene una de sus manifestaciones en los derechos democráticos y de propiedad; a través de estos, el hombre puede alcanzar la libertad y su bienestar general.

Observamos entonces cómo a través de la libertad se llegaba a obtener un bienestar, por este motivo, no debía existir interferencia del Estado. En vista de lo anterior, la libertad es previa al Estado, por lo cual los derechos adquieren un carácter de límite al actuar de los poderes públicos. Se afirma entonces que el Estado mantiene unas condiciones básicas para su garantía, pero es la sociedad la que delimita los casos en que es capaz de autorregularse sin necesidad de la intervención estatal (Böckenförde, 1993). 
En lo que respecta al derecho administrativo en esta época era entendido como "una disciplina que, bajo el imperio de la ley, orienta las actividades del Estado moderno y democrático, puesto que su principio articulador es el interés que resulta de la asociación de los ciudadanos" (Ferraro Cibelli, 2009, p. 28).

Lo anterior implicó un sometimiento absoluto a la ley por parte de los poderes públicos, incluido el Ejecutivo. Esto trajo como resultado que tanto la Administración como el Gobierno solo podían hacer lo que la ley establecía, por lo que su actitud frente a los administrados era de abstención y no de interferencia.

No fue sino hasta final del siglo XIX e inicio del XX cuando se percataron que la revolución liberal no satisfacía las necesidades básicas de todos los habitantes. Esto ocasionó el problema de la distinción abrupta entre la clase propietaria y la clase trabajadora. Esta última se identificaba por su gran número de necesidades insatisfechas (Ferraro, 2009; von Stein, 1850). Al respecto, Alonso (2009) sostiene que las transformaciones de la sociedad acabaron con la armonía espontanea que se predicaba en el modelo liberal. Así, asevera la doctrinante que se generó una gran concentración de capitales, que implicó la formación de grandes monopolios y de forma simultánea, la sociedad trabajadora sufrió un "proceso de depauperación" que vino acompañado del éxodo de las zonas rurales a las urbes generándose desempleo, pobreza $\mathrm{y}$ falta de oportunidades.

En esta situación se hizo necesario que el Estado interviniera en los asuntos económicos y sociales de la comunidad a través de políticas públicas tendientes a controlar y garantizar las prestaciones básicas sociales (García y Alonso, 1989. Debemos manifestar que la socialización del Estado no fue inmediata, sino que la podemos concretar en tres fases: la primera, se caracterizó por la producción de legislación ordinaria por parte de los países más industrializados, con lo que se otorgó una serie de beneficios sociales a los trabajadores como seguros de enfermedad, seguros contra accidentes laborales, sistema de jubilación y regulación de trabajos peligrosos ${ }^{2}$.

La segunda, se identificó con la instauración de sistemas de seguridad social. Es de resaltar que en 1911 en Gran Bretaña se instauró un sistema de Seguridad Social que se materializó a través del National Insurance Act. Esto generó una intervención más asidua por parte del Estado en los temas sociales, que debía brindar no solo unas garantías formales, propias del modelo liberal, sino que también se le exigió que todas esas garantías y derechos consagrados en la ley debían materializarse. En este punto se puede hablar de un Estado material de Derecho (Verdú, 1955).

Finalmente, cuando cobró carta de naturaleza en las constituciones, encontramos la última fase o etapa en la consolidación del modelo social. Podemos hacer referencia a la Constitución de Querétaro de 1917, a la de Weimar de 1919 y a la de la Segunda República de España de 1931. Al incorporarse en la Norma Superior el postulado social, este deviene en un propósito que el Estado debe realizar y se logra a través de la igualdad material, los derechos sociales y la intervención pública en la economía.

Es necesario apuntar que el concepto $E s$ tado social de derecho fue acuñado por Heller en 1929 (Abendroth, 1973; Carmona, 2000; Heller, 1985; Rodríguez-Arana, 2017). Del análisis hecho por el autor se advierte su intención de reposicionar Estado de derecho, del cual se aprovecharon los regímenes totalitarios, que justificaron sus actos por el deber de sometimiento a la ley. Por lo tanto, lo que intenta el componente social es imponer una barrera a los posibles abusos y desigualdades del modelo liberal. Así, el autor alemán intenta armonizar los dos modelos, es decir, el liberal y el social. Sin embargo, esta posición no fue acogida por toda la doctrina. De allí surgió el debate entre 
Abendroth (1973) y Forsthoff (1886) quienes discutieron respecto a la compatibilidad de este nuevo modelo de Estado (Solórzano, 2016).

En este punto, no hay que desconocer la importancia de la democracia en todo el proceso mencionado. Se reconoce que el fundamento de los poderes públicos nace de la soberanía popular y la participación de los ciudadanos se hace de forma directa o por medio de sus representantes. Finalmente, las constituciones preceptuaron el pluralismo político y social como valor de convivencia (Solórzano, 2016).

Paralelamente, en materia del Ejecutivo sostiene Rodríguez-Arana (2017) que la constitución empieza a sustituir a la legalidad administrativa como fuente principal del Derecho, es decir, la Administración y el Gobierno van más allá de la legalidad administrativa positiva y negativa, y se hacen parte fundamental en la consecución del bienestar general. Al respecto Martin Retortillo Baquer (2011) sostiene que cuando se hacen exigibles los derechos sociales, se termina la idea en la que la Administración adopta una postura pasiva y por el contrario deberá ser la protagonista en la protección que se le debe al individuo.

El establecimiento de la cláusula de Estado social y democrático de derecho en las constituciones implicó una serie de obligaciones por parte de los poderes públicos. Como mencionamos antes, el Estado debe tener una actitud más proactiva en la consecución de lo que Forsthoff (1886) considera es el mínimo vital. Sin embargo, el fundamento y la razón de ser de esta obligación nacen de la dignidad, entendida como principio cuyo titular es la persona y es previo a la formación del Estado. Además, es a través de este principio por el cual el ordenamiento jurídico constitucional encuentra su fundamento (Fernández, 1996; 2003; Häberle, 2008; Martínez, 2013; Solórzano, 2016).

Teniendo de soporte lo anterior, los derechos constitucionales resultan en el derrotero que sirve de guía en el quehacer de los poderes públicos. Así los derechos de la persona adquieren una visión que, en términos del Derecho administrativo, permite la consecución del interés general (Rodríguez-Arana, 2010). De acuerdo con el modelo de Estado social y democrático de Derecho, los derechos fundamentales se tornan una fuente de inspiración en el actuar de los poderes públicos. Para fundamentar esta posición consideramos adecuado apoyarnos en la teoría del doble carácter de los derechos fundamentales. Los derechos no solamente tienen un carácter subjetivo, también protegen relaciones objetivas que dan sentido al actuar de los poderes públicos.

En relación con el carácter subjetivo, podemos sintetizarlo en la protección de los derechos fundamentales por parte del Estado. Por lo tanto, tienen implícita una posición de defensa que toma al individuo como un ser portador de unos derechos que deben ser garantizados (Häberle, 2004; Hesse, 1991; Schneider, 1979; Tolé Martínez, 2006).

Häberle (2004) estima que darle una visión unidimensional a los derechos fundamentales es insuficiente en las relaciones que mantienen las personas con los poderes públicos, es decir, no se puede limitar a la defensa de los derechos como barrera a los abusos de poder por parte del Estado. Por el contrario, estos tienen implícitos fines, mandatos, principios y valores que permiten la construcción de un modelo de Estado. Como consecuencia de lo anterior, se genera un carácter objetivo de los derechos fundamentales el cual no se contrapone al carácter subjetivo; de hecho, la conjugación de estas visiones permite la concreción del carácter subjetivo (Hesse, 1991).

Sobre el carácter objetivo cabe decir que abarca a todos los derechos, incluidos los sociales, de esta forma y teniendo en cuenta que son el resultado de la garantía del principio de dignidad, irradian el actuar público. Esto implica que obligan a los poderes públicos a su 
observancia. Aunado a lo anterior, imponen un deber proactivo al Estado en la concreción y protección de los derechos fundamentales (León Alonso, 2009). Esta irradiación hace que los poderes públicos tengan presente en todo momento los derechos de las personas. De hecho, es a través de estos por los cuales la actividad pública encuentra su razón de ser, por cuanto se imponen como unos principios supremos dentro del ordenamiento jurídico por los cuales se pueden alcanzar las finalidades que el constituyente plasmó en la Carta (Hesse, 2001).

De igual forma, a fin de darle mayor sustento al argumento de que los derechos fundamentales sirven como fuente de inspiración al quehacer de los poderes públicos, podemos remitirnos a la teoría de los derechos fundamentales de Alexy (2007), este autor sostiene que las normas de derecho fundamental pueden ser reglas o mandatos de optimización. En razón de lo anterior, los derechos fundamentales no solo se imponen como normas que prohíben o permiten algo, también acaecen en principios que irradian el ordenamiento jurídico y vinculan a los poderes públicos en su consecución (Sentencia constitucional 587, 1992; Sentencia de tutela 596, 1992; sentencia tribunal constitucional 53, 1985).

Así, el carácter subjetivo de los derechos fundamentales obliga de manera directa a todos los poderes públicos, incluyendo al Ejecutivo, donde encontramos a la Administración y el Gobierno.

En este punto cabe hacer una claridad entre la diferencia entre el Gobierno y la Administración. Se debe empezar por mencionar que existe concurrencia de competencias en cargos públicos que hace difícil la diferenciación entre las actividades ejercidas por el Gobierno o por la Administración, es el caso del presidente o de los ministros del Gobierno. Pese a las situaciones que se pueden dar en la praxis consideramos que el Gobierno tendrá a cargo la dirección política interior y exterior, así como la administración civil y militar. Todas las decisiones en estas materias deben ser adoptadas obligatoriamente por el colectivo de las personas que la Constitución tipifica conforman el Gobierno (Santamaría, 1988).

De otro lado, la Administración se configura por una serie de órganos jerárquicos al servicio de la comunidad con el fin de satisfacer el interés general. Estos órganos son el brazo ejecutor del Gobierno y se les encomienda la implementación de las políticas públicas dentro del marco legal. La anterior división no es óbice para que el Gobierno y la Administración actúen de forma separada; por el contrario, su quehacer debe caracterizarse por la interrelación mutua a fin de poder ejercer una función armónica y poder cumplir con los fines constitucionales.

Consideramos por lo tanto que la Administración cumple con una función esencial en la materialización de los derechos. En este sentido, Parejo (2012) nos recuerda que tiene gran relevancia política y jurídica y que su estructura se encuentra presente en casi todos los ámbitos de la vida del individuo, y tiene como tarea "cumplir funciones y proveer (...) garantizar (...) la provisión de bienes y servicios indispensables (seguridad, sanidad, educación, infraestructuras, transporte, suministro de energía, entre otros muchos)" (p. 15). De lo anterior, se puede inferir que la materialización de los derechos sociales repercute en gran parte en el quehacer del Ejecutivo, en el entendido que es el Gobierno quien diseña las políticas públicas ${ }^{3}$ y será la Administración a través de sus instituciones quien las implemente.

Por su parte Forsthoff (1886) consideró que para la realización y concreción de los derechos sociales es necesario la intervención del Legislador y del Ejecutivo, ya que para él eran disposiciones de contenido programático y no son de aplicación inmediata. Así, se hace necesaria su regulación de acuerdo al momento polí- 
tico. Si bien el debate de la inclusión del Estado social en las constituciones ya fue resuelto y es aceptada su armónica relación con el Estado de Derecho, la posición del profesor alemán nos sirve para denotar una situación que en la actualidad tiene suprema importancia en la función ejecutiva.

En la actualidad se acepta la primacía de los derechos sociales en nuestro modelo de Estado. Aquellos requieren para su concreción la voluntad del Legislativo y, posteriormente, el diseño de los instrumentos por medio de los cuales estos derechos pueden ser disfrutados por la sociedad en general (Carbonell, 2015). Este es un problema con el que cuentan los derechos sociales, ya que muchas veces la falta de concreción se reduce a la morosidad de desarrollo legislativo o a la no intención por parte del Gobierno en el desarrollo de políticas públicas tendientes a su concreción. En vista de lo anterior y retomando las palabras de Ferraro (2009), la Administración es la estructura fundamental del Estado actual, por eso debe tener clara su posición e importancia en el logro y la satisfacción de los derechos del individuo.

Hoy día podemos ver cómo las constituciones occidentales (piénsese en la colombiana, la española o la italiana) hacen énfasis en instar al buen comportamiento de las administraciones. Encontramos así en el artículo 103 de la carta española, el 209 de la Constitución política de Colombia o el artículo 97 de la Constitución de la República italiana (Retortillo, 2011).

\section{El interés general como punto de concreción del postulado social dentro de la organización administrativa}

De acuerdo con el desarrollo y las transformaciones del modelo de Estado llegamos al punto en que la Administración es elemental para la concesión del postulado social (Rodríguez, 2015). Es a través del interés general por medio del cual los derechos fundamentales encuentran protección en el quehacer administrativo (Vala Kristjánsdóttir, 2013). Al tenor de lo manifestado la Constitución Colombiana establece en el artículo 209 que la función ejercida por la Administración se encuentra al servicio de los intereses generales. De forma concomitante, el artículo primero de la Carta preceptúa como uno de los fines estatales la prevalencia del interés general.

Ahora bien, es clara la abstracción del concepto de interés general (De la Morena y De la Morena, 1983; Nieto, 1991). Esto no implica que no tenga importancia a la luz del derecho público; de hecho, en un Rapport del año 1999, el Consejo de Estado francés sostuvo que el interés general es la piedra angular de la acción pública y debe ser tenido en cuenta para la toma de decisiones públicas, ya que dota de legitimidad el quehacer administrativo (Conseil d'État et la Jurisdiction Administrative, 1999).

Rodríguez (2003) sostiene que el interés general viene a determinarse por la afectividad de los derechos fundamentales. De igual manera, manifiesta que en el modelo de Estado actual estos derechos se tornan en la razón de ser de la Administración pública. Estamos inclinados a creer que el interés general es un principio que debe tener como cimiento el desarrollo de los derechos fundamentales. Así, la función administrativa descansaría en los postulados del modelo de Estado social y democrático de derecho (Rodríguez, 2010; Minnicelli, 2012).

Al respecto, la Corte Constitucional de Colombia en la Sentencia T-428 de 1992 arguyó que el interés general debe ser aplicado armónicamente con los demás principios constitucionales consagrados en la Carta y en atención al modelo de Estado. De igual manera, que el interés general en su aplicación no debe conculcar derechos fundamentales pues esto resultaría errado e ilógico, ya que se parte del supuesto que la persona es un fin per se, por lo que el progreso del Estado no puede encontrar justificación en la lesión de los derechos de la persona (Sentencia T-428, 1992). 
Se puede inferir que el Estado encuentra su vinculación entre los derechos fundamentales y su quehacer en el interés general, que viene a ser la piedra angular de la actividad pública, en especial en lo concerniente a la administración y el gobierno. Así, vemos que el interés general da vida a ese carácter objetivo de los derechos fundamentales que en líneas anteriores explicamos. Sostuvimos que los derechos fundamentales irradian el quehacer público. Entonces en lo que concierne al Ejecutivo, el interés general es el recordatorio permanente de brindar y cumplir con todos los derechos que se encuentran en la Carta; lo que implica, si es necesario, modificar las instituciones públicas. No se debe perder de vista que el Estado es una organización a favor de las necesidades sociales (Rivero, 1999).

Al respecto, Rotondo (2015) considera que el Derecho Público deja de ser visto como el derecho que estudia el poder, la organización administrativa o los servicios públicos y se centra en el estudio de la consecución del interés general, el cual se alcanza y se materializa si se respetan los derechos de las personas. Sobre este argumento, el Ejecutivo se encuentra obligado a mejorar las condiciones de vida de las personas. Lo anterior implica que no solo se satisfagan los derechos que sirven de límite al actuar del Estado, sino que la Administración y el Gobierno se hagan parte activa en su satisfacción, como encargados de materializar muchos de los derechos sociales. Esto se logra a través del diseño correcto de políticas públicas que estén dirigidas a la prestación permanente de servicios, como salud, educación, trabajo entre otros, que redundarán en la consecución de un bienestar (Sandoval, 2011).

En este estado del debate no sobra mencionar lo sostenido por De la Morena y De la Morena (1983). El autor arguye que el interés general debe encontrarse presente en todas las normas administrativas, en consecuencia, en los actos emanados por la organización administrativa y en su quehacer diario. Adicionalmente, Rodríguez-Arana (2012) considera que es un principio que dota de sentido a la actividad administrativa, al tener la obligación de satisfacer las demandas de manera objetiva y a la luz de los demás valores y principios constitucionales exigidos dentro del marco de modelo de Estado social y democrático de derecho (Solórzano, 2016).

\section{El buen gobierno y la buena administración como principios que refuerzan el papel de garante de los derechos sociales en la actualidad}

En el plano normativo existen una serie de garantías para que la Administración y el Gobierno se sometan al interés general y lo hagan a través del cumplimiento de todos los mandatos, los principios, los fines y los valores constitucionales (von Bogdandy y Huber, 2013). Sin embargo, vemos como el Ejecutivo está sometido a constantes escándalos de corrupción y de ineficiencia al interior de su organización (Guzmán, 2014; Nevado-Batalla, 2014). Además, existe una constante insatisfacción ciudadana, el debilitamiento institucional y el desmantelamiento al que se han sometido las garantías de los derechos sociales (De Cabo Martín, 1986; 2006; Pisarello, 2012; Larach, 2015; Viciano y Martínez, 2017).

En el contexto Iberoamericano, Ferraro (2009) reflexiona que la estructura administrativa no ha suplido esas necesidades básicas, lo que se demuestra en los altos índices de pobreza que alcanzan niveles hasta del cincuenta por ciento en algunos países (Naciones Unidas, 2016). Existe una especie de fracaso en la implementación de la política social. Si bien hay legislación y programas tendientes a generar su desarrollo, en los países de Iberoamérica no se han podido obtener resultados duraderos por la falta de una correcta implementación de políticas públicas. Todo esto lleva a concluir que existe una debilidad en las instituciones estatales y hay una carencia en la generación de una Administración pública capaz de obtener resultados de manera uniforme y persistente (Ferraro, 2009). 
Esto ha implicado que la doctrina genere un concepto nuevo en el que subyacen todas las normas constitucionales que obligan al Gobierno y a la Administración a que su actuar sea adecuado en términos constitucionales. Estos dos conceptos se conocen como buen gobierno y buena administración. No se excluyen, sino que se complementan y tienen una misma tarea: la satisfacción de las necesidades de los habitantes con respeto por el ordenamiento constitucional. Al respecto, en The Federalist se sostiene que "the true test of a good government is, its aptitude and tendency to produce a good administration" (Hamilton, Jay y Madison, 2001). Lo anterior, sirve para manifestar que estos conceptos refuerzan la realización del interés general al tener como propósito la formación adecuada de una estructura administrativa apropiada a las pretensiones de la sociedad.

Consideramos que el buen gobierno y la buena administración son principios. Siguiendo la teoría de Alexy (2007), los principios son mandatos de optimización, en el sentido que son "normas que ordenan que algo sea realizado en la mayor medida posible dentro de las posibilidades jurídicas reales existentes" (p. 86). Si aplicamos esta teoría al quehacer del Ejecutivo, se dirige al sometimiento de las normas constitucionales.

Según García de Enterria (1962), quien expresa que una de las maneras de controlar el actuar de la organización administrativa es el sometimiento a los principios, permite esto que el actuar discrecional esté limitado y regulado. En este orden de ideas, el buen gobierno y la buena administración se imponen como principios que obligan de manera categórica el adecuado quehacer de la función ejecutiva.

Es de manifestar que el contenido del buen gobierno y la buena administración no es una cuestión de nuevo cuño, son todos esos principios, derechos, mandatos, fines, valores y anhelos que se consagraron en la constitución y que, está supuesto, la Administración y el
Gobierno deben cumplir. No obstante, y pese a la realidad pública, se hace necesario reforzar la garantía de la norma constitucional y el sometimiento a la legalidad desde el punto de vista de la organización administrativa. Para ello, Freitas y Teixeira (2013) nos recuerdan la obligación que tiene el ejecutivo de aplicar la Constitución de manera oportuna y de oficio, al cumplir con todos los deberes que la Norma Superior establece.

Pero para su alcance se requiere reforzar los principios de transparencia y la participación, que son piezas claves en la formación del buen gobierno y la buena administración (Ponce, 2016; Rivero, 2015; Rodríguez, 2010, Cornelio, 2018). La transparencia debe ser la regla, mientras que el ocultismo y el secreto en la actividad del ejecutivo deben ser la excepción (Bobbio, 1986). Con una función administrativa más transparente y abierta, habrá un halo de claridad y tranquilidad del quehacer ejecutivo ${ }^{4}$, además, la transparencia fomenta la participación. Si hay una organización administrativa más franca, cada vez más los ciudadanos se verán atraídos a participar en los asuntos públicos, ya sea haciendo parte en la toma de las decisiones o en el ejercicio de los controles como es la rendición de cuentas.

La Estrategia 186 para el Fomento del Buen Gobierno en la política alemana de desarrollo, proferida en 2009 por el Ministerio Federal de Cooperación Económica y Desarrollo de Alemania, consideró que para la garantía de los derechos y, en consecuencia, el logro de un buen gobierno, es fundamental la participación y el compromiso de toda la sociedad civil en los asuntos públicos. El documento reivindica el rol de los derechos de la persona, el postulado democrático y el del Estado de Derecho. También garantiza la correcta oferta y el control de los servicios públicos, con lo que se protegen los derechos a la salud, la educación, entre otros. De este doble rol la sociedad civil deviene en un interlocutor determinante en la consecución del modelo de Estado. Igualmente, el Ejecutivo 
debe asumir las funciones de regulación y de diseño de políticas públicas adecuadas apoyándose claramente en la actividad legislativa.

Entonces, para la consecución del buen gobierno y la buena administración se debe romper el concepto tradicional de la administración y el gobierno como únicos actores en la toma de decisiones públicas. En su lugar, se toma el concepto de gobernanza como un modelo de gestión administrativa inclusiva y garante de la satisfacción de necesidades de las personas $^{5}$.

Nieto García (1975) pone de manifiesto que la participación es una necesidad para la mejora de la organización administrativa.

En los tiempos que corremos, hablar de intereses colectivos es hablar de democracia, porque es permitir que amplios sectores sociales, a los que son en parte inaccesibles tanto los mecanismos forenses como los políticos, puedan participar en la vida pública. (p. 26).

Lo mencionado sirve para reafirmar la centralidad de la persona en la actividad administrativa y en la satisfacción de los derechos, incluyendo los sociales. Una constante presencia de la comunidad en el ejercicio de la función ejecutiva permite la satisfacción del postulado social por cuanto se atenderán de primera mano las necesidades de la comunidad, esto redundará en una garantía de la igualdad material. De otro lado, se tendrá en el quehacer del Gobierno y la Administración permanentemente presente la dignidad del individuo, elemento esencial para la consecución del modelo actual de Estado. Aquí no se debe perder de vista el carácter de servidumbre de la Administración y el Gobierno, razón por la cual hablamos de servidores. Esto lleva a inferir que las personas que ejercen estas funciones prestan sus servicios a las personas y es en este punto junto con la dignidad y los valores que la persona adquiere un papel preponderante en la actividad administrativa y gubernamental.
Si se tiene presente la primacía de la persona y la prioridad de la organización administrativa de satisfacer las necesidades, la legalidad y demás principios que obligan a la Administración y el Gobierno, tendrán un mejor campo de desarrollo. En este sentido, el buen gobierno y la buena administración se imponen como un supra-principio que acumula todas las normas constitucionales e insta al Ejecutivo a que su quehacer esté acorde con el interés general, y como resultado se protejan y garanticen los derechos de las personas.

La Estrategia 186 de 2009 es de suma importancia para la realización de los derechos humanos y el fomento del buen gobierno. Teniendo como base la Declaración del Milenio de 2000, se afirmó que cuando el Estado promociona los derechos humanos se encamina hacia el desarrollo. La normatividad internacional está de acuerdo con la necesidad de protección de los derechos de las personas y la importancia que estos tienen en el acontecer del Estado. Por lo tanto, el Ejecutivo, como uno de los poderes públicos, debe tomar en serio la realización de los derechos del individuo, garantizándolos a toda costa, inclusive frente a los fenómenos actuales de globalización en donde muchos de los compromisos internacionales que adquieren los Estados lesionan la garantía de los derechos ${ }^{6}$. Esto se logra al generar transformaciones en su interior, las cuales permitirán que su actividad sea más respetuosa con los derechos de las personas.

En primer término, resulta evidente, como lo argumenta Freitas (2000), que los poderes públicos no pueden excusarse del deber constitucional que tienen en la garantía y eficacia de los derechos fundamentales al argüir la imposibilidad de satisfacer las demandas sociales de todas las personas, en temas de protección de derechos sociales $v$. gr. la salud pública ${ }^{7}$, en especial. 
De igual forma, consideramos que en términos jurídicos una buena administración y un buen gobierno se alcanzan con una adecuada actividad de prevención, asesoría y defensa ${ }^{8}$. Este conjunto de actividades lo denominamos como la asistencia jurídica al Estado y permite la garantía no solo de la legalidad de la actuación administrativa, sino además del interés general.

La función ejecutiva debe ser profesional e innovadora, por ello se requiere que ingresen profesionales adecuados a través de concursos de mérito, lo que en parte garantiza que solo los más aptos ocupen los puestos públicos. Debemos olvidarnos del uso abusivo que se les da a las interinidades (Rivero, 2012), y a los contratos de prestación de servicios los cuales cada vez politizan y desfiguran el objetivo de la relación laboral y van en deterioro de la importancia de contar con profesionales idóneos que ejerzan una actividad pública adecuada. De forma paralela al ingresar a prestar las labores, el profesional debe contar con una ética férrea que impida desviar la objetividad y la máxima que es el interés general. Para ello se hace necesario contar con mecanismos disciplinarios certeros y severos que castiguen los hechos constitutivos de mal gobierno o mala administración.

El buen gobierno y la buena administración no se logra solo con castigar a los miembros de la administración, los gobernantes deben ejecutar políticas públicas oportunas e idóneas de acuerdo con las necesidades de la población. Con una adecuada planeación e implementación se procurará la garantía de los derechos sociales; para su materialización, se hará necesaria también la participación ciudadana, la cual redundará en que este tipo de políticas se implementen de forma adecuada y sean dirigidas a aspectos que la sociedad en verdad necesita, piénsese en los servicios de salud o educación públicos los cuales en ocasiones no son los más óptimos.

\section{Conclusión}

El ser humano goza de primacía al interior de los poderes públicos, dentro del ordenamiento jurídico. Es por ello que los derechos fundamentales devendrán en la guía del quehacer estatal. Esta afirmación no debe perderse de vista, ya que todo el Estado existe exclusivamente para proteger a la persona y su entorno.

Es así como el Gobierno y la Administración juegan un papel determinante y primordial en la garantía de esa protección que debe darse a cada una de las personas. Por cuanto, es la función del Estado que tiene mayor capacidad de materializar las necesidades de la comunidad. Como consecuencia, y teniendo presente el modelo de Estado actual, se requiere una intervención pública constante que incluya la guarda de todos los derechos constitucionales. Esto genera un nuevo deber en virtud del postulado social y es la satisfacción de los derechos sociales y la garantía de la igualdad material. Para su consecución se requiere un sometimiento cualificado a la ley, es decir, debe cumplirse al tener en cuenta los derechos fundamentales y la dignidad.

Se han creado los principios de buen gobierno y de buena administración en los que subyacen todos los mandatos, valores, principios y derechos que obligan al ejecutivo. Estos nuevos principios permitirán que el quehacer ejecutivo no sea arbitrario y desordenado ya que cumplirá con el objetivo de guiarlo hacia el sometimiento de la constitución.

Para la consolidación de estos principios se hace necesario repensar el funcionamiento de la administración y el gobierno. El quehacer del ejecutivo no se va a ceñir a los principios del buen gobierno y la buena administración únicamente con la elaboración de normatividad que al final quede escrita en el papel y no tenga una eficacia material. Es cierto que la tipificación en una norma del buen gobierno y la buena administración ayuda a que estos principios sean 
exigibles, pero no debe ser la única herramienta con que cuente el Ejecutivo.

Se hace necesario verificar que en su estructura y procedimiento, se tenga como norte la protección de la dignidad de la persona, en todo momento. Esto se hace por ejemplo, eliminando duplicidades en las funciones de la Administración que atentan a todas luces con los principios de fácil acceso a la Administración y de economía. También se deberá cambiar la percepción del buen gobierno y la buena administración como una garantía procedimental únicamente presente en la etapa del procedimiento administrativo que se relaciona con el ciudadano. Así por ejemplo es errada la concepción que se tiene en Europa de la buena administración ${ }^{9}$, por cuanto la limitan al trato que el ciudadano debe recibir. Sin embargo, si queremos que el contacto del servidor público sea garante del procedimiento y respetuoso con el ciudadano, el quehacer administrativo desde su inicio debe someterse a los postulados constitucionales. Esto garantiza que al momento en que la Administración o el Gobierno entre en contacto con el individuo, sus derechos constitucionales estén plenamente garantizados. De igual forma, no se debe considerar el buen gobierno y la buena administración como una cuestión que solo esté presente en el procedimiento administrativo, sino que debe verse reflejado en todo su quehacer.

La participación de la comunidad es imprescindible. Debemos ver que en la actualidad hay mecanismos de participación directa que acercan más al individuo y los asuntos públicos, algo necesario para que el Gobierno y la Administración no se alejen de la realidad social e implementen políticas públicas oportunas. Finalmente, podemos decir que esa importancia y necesidad que tiene el ejecutivo en la materialización de los derechos sociales podrá darse de mejor forma si se somete al principio del buen gobierno y de la buena administración.

\section{Referencias}

Abendroth, W. (1973). Sobre el concepto de estado de derecho democrático y social tal como se formula en la Constitución de la RFA. En Autor (Ed.), Sociedad antagónica y democracia política: ensayos sobre sociología política (pp. 266-272). Barcelona: Grijalbo.

Alexy, R. (2007). Teoría de los derechos fundamentales. Madrid: Centro de estudios políticos y constitucionales.

Barra Gallardo, N. (2017). El control social en la prevención de malas prácticas administrativas y la corrupción especial atención a la participación ciudadana. Salamanca: Universidad de Salamanca.

Bobbio, N. (1986). El futuro de la democracia. México: Fondo de la cultura económica.

Böckenförde, E. W. (1993). Escritos sobre derechos fundamentales (1. ${ }^{\mathrm{a}}$ Ed.). BadenBaden: Nomos.

Calvo Sánchez, M. (2015). Patrón de conducta exigible a una buena Administración Pública Sanitaria. AIS: Ars Iuris Salmanticensis, 2(2), 53-70

Carbonell, M. (2015). Eficacia de la Constitución y derechos sociales: esbozo de algunos problemas. Revista de Derecho Público, (70), 23-47. doi: 10.5354/07195249.2015.37735

Carmona Cuenca, E. (2000). El estado social de Derecho en la constitución. Madrid: Consejo Económico y social.

Conseil d'État et la Jurisdiction Administrative. (1999). Réflexions sur l'interêt général [Rapport Publique]. Francia.

Cornelio Zamudio, L. (2018). El derecho a la buena administración pública. Perfiles de las ciencias sociales, 5, 315-344. 
De Cabo Martín, C. (1986). La crisis del Estado social. Barcelona: PPU.

De Cabo Martín, C.(2006). Teoría constitucional de la solidaridad. Madrid: Marcial Pons.

De la Morena y De la Morena, L. (1983). Derecho administrativo e interés público: correlaciones básicas. Revista de Administración Pública, 100-102(fas. 1), 847-880.

Fernández Segado, F. (1996). La dignidad de la persona como fundamento de sus derechos. Revista de Derecho Público, 6.

Fernández Segado, F. (2003). Estudios jurídico-constitucionales. México: Universidad Nacional Autónoma de México.

Ferraro Cibelli, A. (2009). Reinventando el Estado: por una administración pública democrática y profesional en Iberoamérica (1. ${ }^{\mathrm{a}}$ Ed.). Madrid: Instituto INAP.

Forsthoff, E. (1886). Concepto y esencia del Estado social de Derecho. En W. Abendroth (Ed.). El Estado social (1. ${ }^{\mathrm{a}}$ Ed.). Madrid: Centro de estudios constitucionales.

Freitas, J., y Teixeira, V. (2013). Omisión Constitucional: una ampliación conceptual en el ámbito de las políticas públicas. Estudios Constitucionales, 1(1), 143-166. doi: $10.4067 / \mathrm{S} 0718-52002013000100005$

García de Enterría, E. (1962). La lucha contra las inmunidades del poder en el Derecho administrativo (poderes discrecionales, poderes de gobierno, poderes normativos). Revista de Administración Pública, 38, 159-208.

García de Enterría, E., y Fernández Rodríguez, T. R. (2006). Curso de Derecho administrativo I (12. ${ }^{a}$ Ed.). Madrid: Thomson.

García Pelayo y Alonso, M. (1989). Las transformaciones del Estado contemporáneo. Madrid: Alianza.
Gómez Puente, M. (2002). La inactividad de la administración (1. ${ }^{\mathrm{a}}$ Ed.). Navarra: Aranzadi.

Guzmán López, J. (2014). La ética pública como instrumento de buen gobierno y de mejora de la gestión: un análisis sobre su implementación en el sexenio de Vicente Fox 2000-2006. [Tesis de doctorado]. Recuperada de TESIUNAM. Dirección General de Bibliotecas. Universidad Nacional Autónoma de México. (oai:tesis. dgbiblio.unam.mx:000713908)

Häberle, P. (2004). Recientes desarrollos sobre derechos fundamentales en Alemania en Nueve ensayos constitucionales y una lección jubilar. Lima: Asociación peruana de derecho constitucional.

Häberle, P. (2008). La dignidad del hombre como fundamento de la comunidad estatal en el derecho alemán. En F. Fernández Segado (Coord.), Dignidad de la persona, derechos fundamentales, justicia constitucional y otros estudios de derecho público. (pp. 175-237). Madrid: Dykinson

Hamilton, A., Jay, J., y Madison, J. (2001). The Federalist. Indianapolis: Liberty Fund.

Heller, H. (1985). ¿Estado de derecho o dictadura? En Autor (Ed.), Escritos políticos. Madrid: Alianza.

Hesse, K. (1991). Grudnzüge des Verfassungsrechts der Bundesrepublik Deutschland. Heidelberg: C.F. Müller.

Hesse, K. (2001). El significado de los derechos fundamentales. López Pina (Ed.), Manual de derecho constitucional (pp. 90-91). Madrid: Marcial Pons.

Larach, C. (2015). Transparencia y buen gobierno en España. Revista Digital de Derecho Administrativo, 13, 255-268. doi: 10.18601/21452946.n13.13 
León Alonso, M. (2009). La protección constitucional de la salud en el marco del Estado social y democrático de Derecho (1. ${ }^{\text {a }}$ Ed.). Salamanca: Ediciones Universidad de Salamanca.

Martin-Retortillo Baquer, L. (2011). De los derechos humanos al derecho a la buena administración. En C. Ávila Rodríguez y F. Gutiérrez Rodríguez (Eds.), El derecho a una buena administración pública y la ética pública (1. ${ }^{a}$ Ed., pp. 43-54). Valencia: Tirant lo Blanch.

Martínez Bullé-Goyri, V. (2013). Reflexiones sobre la dignidad humana en la actualidad. Boletín Mexicano de Derecho comparado, 46(136), 39-67. doi: 10.1016/ S0041-8633 (13)71121-9

Minnicelli, A. (2012). Principios generales y politicas públicas: herramientas del Derecho Administrativo para optimizar la satisfacción de necesidades y universalizar los derechos humanos en un Estado eficaz. [Tesis de doctorado]. Gredos, Universidad de Salamanca. Recuperado de: http://hdl.handle.net/10366/121197.

Nevado-Batalla, P. (2014). Paradigmas de la mejora y el control de la gestión pública (transparencia, responsabilidad y calidad de los servicios). Iustitia, 12, 329-349.

Nieto García, A. (1975). La vocación del Derecho administrativo en nuestro tiempo. Revista de Administración Pública, 76, 9-30.

Nieto García, A. (1991). La administración sirve con objetividad a los intereses generales. En S. Martín- Retortillo (Ed.), Estudios sobre la constitución española: homenaje al profesor Eduardo García de Enterría (pp. 2185 -2254). Madrid: Civitas.

Parejo-Alfonso, L. (2012). Lecciones de derecho Administrativo (5. ${ }^{\mathrm{a}}$ Ed.). Valencia: Tirant lo Blanch.
Peces-Barba, G., y Dorado, J. (2003). Derecho, sociedad y cultura en el siglo XVIII Tomo II vol. I. En F. Ansuátegui Roig, J. M. Rodríguez Uribe, G. Peces-Barba Martínez, E. Fernández García (Coords.), Historia de los derechos fundamentales (pp. 3-220). Madrid: IDHBC-Dykinson.

Pisarello Prados, G (2012). El constitucionalismo social ante la crisis entre la agonía y la refundación republicano-democrática. Revista Derecho del Estado, 28, 55-75.

Pomed Sánchez, L. (1997). El acceso a los archivos administrativos: el marco jurídico y la práctica administrativa. Revista de Administración Pública, 142, 439-479.

Ponce Solé, J. (2016). El derecho a una buena administración y el derecho administrativo iberoamericano del siglo XXI. Buen gobierno y derecho a una buena administración contra arbitrariedad y corrupción. En H. Rosatti y E. Alonso Regueira (Eds.) El control de la actividad estatal (pp. 220-247). Buenos Aires: Asociación de Docentes Facultad de Derecho y Ciencias Sociales Universidad de Buenos Aires.

Prats Catalá, J. (2004). Las transformaciones de las Administraciones Públicas de nuestro tiempo. En F. Sainz Moreno (Ed.), Estudios para la Reforma de la Administración Pública (pp. 27-102). Madrid: INAP.

Prats Catalá, J. (2005). De la burocracia al "management", del "management" a la gobernanza: las transformaciones de las administraciones en nuestro tiempo. Madrid: INAP.

Rivero Ortega, R. (1999). El estado vigilante: consideraciones jurídicas sobre la función inspectora de la Administración. Madrid: Tecnos. 
Rivero Ortega, R. (2012). La necesaria innovación de las instituciones administrativas: organización, procedimiento, función pública, contratos administrativos y regulación. Madrid: INAP.

Rivero Ortega, R. (2016). Derecho Administrativo. Salamanca: Ratio Legis.

Rivero Ysern, E. (16 de junio de 2014). En torno al interés general. Conferencia dentro de los XXXV cursos de especialización en derecho de la Universidad de Salamanca, España [video]. Recuperado de https://www.youtube.com/ watch? $\mathrm{v}=$ mgwCeDMG5-c

Rodríguez-Arana, J. (2003). Los derechos fundamentales en el Estado social y el derecho administrativo constitucional. Anuario de Derecho Administrativo, 10, 59-68.

Rodríguez-Arana, J. (2012). El interés general como categoría central de las actuaciones públicas. Revista de La Asociación Argentina de Derecho Administrativo, 8, 25.

Rodríguez-Arana, J. (2012). Interés general, derecho administrativo y Estado de Bienestar. Madrid: SYNTAGMA/IUSTEL.

Rodríguez-Arana, J. (2015). La cláusula del Estado Social y los derechos fundamentales sociales. Revista Eurolatinoamericana de Derecho Administrativo, 2(1), 155-183. doi: 10.14409/rr.v2i1.4635

Rodríguez-Arana Muñoz, J. (2017). Derecho administrativo y derechos sociales fundamentales. Revista de Derecho, 6, 95-105.

Rotondo, F. (2015). Derechos fundamentales y derecho administrativo. Revista de Derecho Público, 47, 87-102.

Rousseau, J.J. (2013). El Contrato social. Madrid: Alianza.

Sabine, G. (2000). Historia de la teoría política. México: Fondo de la cultura económica.
Santamaría Pastor, J. (1988). Gobierno y Administración. Revista Documentación Administrativa, 215, 74.

Sandoval Vásquez, A. (2011). Derechos Humanos y políticas públicas. Revista Reflexiones, 90(2), 101-114.

Schneider, H-P. (1979). Peculiaridad y función de los derechos fundamentales en el Estado constitucional democrático. Revista de Estudios Políticos, 7, 33.

Solano, N. y Sepúlveda, M. (2008). Metodología de la investigación social jurídica. Bogotá: Ibáñez.

Solórzano Quintero, J. F. (2016). La asistencia jurídica pública al Estado y su influencia en la actuación del poder Ejecutivo (1. ${ }^{a}$ Ed.). Salamanca: Ediciones Universidad de Salamanca. doi: 10.2307/j.ctt1kk66pp

Solórzano Quintero, J. F. (2017). Los tratados bilaterales de protección de inversiones y su sometimiento a los derechos humanos y un breve excursus para el caso colombiano. Revista Estudios Socio-Jurídicos, 19(2), 223-258. doi: 10.12804/revistas.urosario. edu.co/sociojuridicos/a.5256

Starck, C. (2008). Los fundamentos filosóficos de los derechos humanos. En F. Fernández Segado (Coord.), Dignidad de la persona, derechos fundamentales, justicia constitucional y otros estudios de derecho público (pp. 395-411). Madrid: Dykinson S.L.

Tamayo Sáez, M. (1997). El análisis de políticas públicas. En R. Bañon y E. Carrillo (Eds.), La nueva Administración pública (pp. 281-312). Madrid: Alianza.

Tolé Martínez, J. (2006). La teoría de la doble dimensión de los derechos fundamentales en Colombia: El estado de cosas inconstitucionales, un ejemplo de su aplicación. Revista Cuestiones Constitucionales, 15, 253-316. 
Vala Kristjánsdóttir, M. (2013). Good Administration as a Fundamental Right. Icelandic Review of Politics and Administration, 9. doi: 10.13177/irpa.a.2013.9.1.12

Verdú, P. (1955). Estado de derecho y Estado social de derecho (1. ${ }^{\mathrm{a}}$ Ed.). Madrid: Graficas Yagües.

Viciano Pastor, R., y Martínez Dalmau, R. (2017). Crisis del Estado Social en Europa: efectos en la generación del constitucionalismo social en América Latina. Revista Justiça do Direito, 31(3), 485-505.

von Bogdandy, A., y Huber, P. (2013). Estado, administración y derecho en Alemania. En A. Von Bogdandy, y O. Mir Puigpelat (Eds.), El derecho Administrativo en el espacio jurídico europeo (pp. 58-124). Valencia: Tirant lo Blanch.

von Stein, L. (1850). Geschichte der sozialen Bewegung in Frankreich von 1789 bis auf unsere Tage (1. ${ }^{a}$ Ed.). Leipzig: Otto Bigand.

\section{Notas}

1 Debemos manifestar que existen manifestaciones previas como la Carta Magna (1225) o el Habeas Corpus (1679), o el Bill of Rights, las cuales solo garantizaban derechos al hombre libre (Starck, 2008).

2 En Alemania en 1884 se profirió una ley referida a los accidentes laborales; en 1889 se instauró el sistema obligatorio de jubilación en este sentido "en Inglaterra la Health and Moral Act to regulate the Labor Bound Children in Cotton Factories, de $1802,(\ldots)$ seguida por leyes de 1819 , 1833, 1842 (mines act), 1844, 1864, 1878, etc. Estableciendo condiciones de trabajo, horarios laborales, descanso semanal, etc. (...) En Alemania, entre 1883 y 1889, se dictaron...Ley de 15 de junio de 1883, que estableció seguro de enfermedad (...) Ley de
1884 sobre accidentes laborales (...) Ley de 1889 sistema obligatorio de jubilación (...) Posteriormente, en 1981, se dictaron otras normas en las que se estableció la jornada laboral máxima. (...) En España, el proceso de reformas sociales se inició tardíamente con la Ley de 24 de julio de 1873 relativa al trabajo de menores (...) Ley de 26 de julio de 1878 sobre trabajos peligrosos de niños, Ley de 13 de marzo de 1900 sobre trabajo de mujeres y niños, Decreto de 20 de junio de 1902 restringiendo la autonomía de las partes en el contrato de trabajo y Decreto de 3 de abril de 1919 estableciendo jornada de ocho horas." (Carmona Cuenca, 2000, pp. 40-42).

3 Entendemos por políticas públicas "como el conjunto de objetivos decisiones y acciones que lleva a cabo un Gobierno para solucionar los problemas que en un momento determinado los ciudadanos y el propio gobierno consideran prioritarios" (Ferraro Cibelli, 2009; Tamayo Sáez, 1997).

4 Respecto del secretismo cabe mencionar que el Estado y, particularmente, el poder ejecutivo ha sufrido una evolución hacia la transparencia, sin embargo, este camino no ha sido fácil ya que en existen influencias de poderes que abogan por el ocultismo. Pomed Sánchez (1997) hace un recuento interesante de la evolución de la transparencia en España que nos recuerda la situación similar que ocurrió en nuestro país. Si observamos la Constitución de Cundinamarca en su Título V, artículo primero, numeral 36 , evidenciamos que era común guardar el secreto de lo que ocurría al interior de ejecutivo so pena de incurrir en traición. Al respecto la norma establece: "Siendo el secreto muy necesario en algunas providencias del Poder Executivo, su violación debe considerarse como delito de traición; y el presidente del Estado debe cuidar de que los dependientes del Tribunal sean de suma fidelidad" (Constitución de Cundinamarca, 
título V, artículo primero, numeral 36,1811). Si comparamos este compendio normativo con la actual Constitución observamos la gran evolución y la gran apertura que han tenido los poderes públicos, a fin que los ciudadanos puedan ser controladores y participes en la toma de decisiones públicas.

5 Respecto de la gobernanza como modelo de gestión administrativa véase Prats Catalá, 2004; 2005.

6 Respecto de la colisión entre el derecho internacional público económico y la garantía de los derechos humanos puede verse Solórzano Quintero, 2017.

7 Respecto de la reserva de lo económicamente posible ver Freitas (2000) y Holmes Stephen y Sunset Cass (2000) The Cost of Rigths: Why Liberty Depends on Taxes (New York, Norton).

8 Respecto de la importancia de la asistencia jurídica pública al Estado véase en extenso a Solórzano Quintero, 2016.
9 La carta de los derechos fundamentales de Europa del año 2000 establece en su artículo 41 que buena administración únicamente es: "1. Toda persona tiene derecho a que las instituciones y órganos de la Unión traten sus asuntos imparcial y equitativamente y dentro de un plazo razonable. 2. Este derecho incluye en particular: el derecho de toda persona a ser oída antes de que se tome en contra suya una medida individual que le afecte desfavorablemente, el derecho de toda persona a acceder al expediente que le afecte, dentro del respeto de los intereses legítimos de la confidencialidad y del secreto profesional y comercial, la obligación que incumbe a la administración de motivar sus decisiones. 3. Toda persona tiene derecho a la reparación por la Comunidad de los daños causados por sus instituciones o sus agentes en el ejercicio de sus funciones, de conformidad con los principios generales comunes a los Derechos de los Estados miembros. 4. Toda persona podrá dirigirse a las instituciones de la Unión en una de las lenguas de los Tratados y deberá recibir una contestación en esa misma lengua." 
